\title{
O CÓDIGO DE DEFESA DO CONSUMIDOR COMO EXPOENTE MÁXIMO DA TEORIA CONTRATUAL PÓS-MODERNA
}

\author{
THE CONSUMER PROTECTION LAW AS MAXIMUM EXPONENT OF \\ POSTMODERN CONTRACTUAL THEORY
}

\author{
${ }^{1}$ Mariana Cristina Garatini \\ ${ }^{2}$ Kelly Cristina Canela
}

\begin{abstract}
RESUMO
O presente trabalho se propõe a demonstrar a existência de uma nova teoria contratual, cujo expoente máximo no Direito Brasileiro é o diploma consumerista, ordenamento que legitimou princípios como a boa-fé e a função social do contrato, afastando as latentes desigualdades oriundas da massificação dos contratos e resultando no equilíbrio real entre contratantes. Para alcançar os fins almejados será feita breve análise do surgimento e evolução dos contratos, do modo como as necessidades da sociedade alteraram gradativamente a forma de contratar até o modelo atual, além de elencar as conquistas desta nova teoria contratual resultado da socialização do Direito.
\end{abstract}

Palavras-chave: Teoria contratual, Direito consumerista, Socialização do direito, Boa-fé, Função social

\begin{abstract}
The present paper intends to demonstrate the existence of a new contractual theory, whose Brasilian Order exponent is the Consumers Law. This legislation legitimate the good-faith and the social function of the contracts principles, removing the mass agreement inequalities and resulting in real balance between contractors. To achieve the objectives will be done a brief analysis of the contracts emergence and evolution, showing how the societies demands change gradually hiring proceedings until nowadays, also will be roster the gains of this new theory as result of the Law's socialization.
\end{abstract}

Keywords: Contractual theory, Consumer law, Law's socialization, Good-faith, Social function

\footnotetext{
${ }^{1}$ Mestre em Direito pela Universidade Estadual Paulista Júlio de Mesquita Filho - UNESP, São Paulo (Brasil). Subcoordenação da Equipe MRV pela Brasil Salomão e Matthes Sociedade de Advogados - BSEM, São Paulo (Brasil). E-mail: marianagaratini@gmail.com

${ }^{2}$ Doutora em Direito pela Faculdade de Direito da Universidade de São Paulo - FDUSP, São Paulo (Brasil). Professora pela Universidade Estadual Paulista Júlio de Mesquita Filho - UNESP, São Paulo (Brasil).

E-mail: kellyccanela@gmail.com
} 


\section{INTRODUÇÃO}

Por proêmio, segundo ENZO ROPPO o "Contrato é a veste jurídico-formal de operações econômicas" (2009, p.11), preceitua que o conceito de contrato deve ser analisado em conjunto com a ideia de circulação de riquezas. Nesses termos, operação econômica deve ser entendida como a atual ou potencial transferência de riquezas, enquanto que esta como todas as utilidades susceptíveis de avaliação econômica.

Com base no conceito acima, temos que no contrato encontra-se a principal fonte de circulação de riquezas do Estado, mas não apenas isso, há que se enaltecer que além da função econômica, o contrato é dotado de função regulatória, ao organizar as relações e detém função social, já que seu exercício esta conectado aos interesses sociais. Tornando-se notória a importância de se proceder à análise deste instrumento sobre a ótica coletiva e da forma como ele é utilizado em prol desta sociedade e de sua economia.

Clarificando, os contratos estão presentes em diversos institutos jurídicos, sendo o mais importante modelo de negócio jurídico bilateral, assim, dotado de função social, atuando diretamente na circulação de riquezas, propaga o capitalismo, bem como o crescimento e desenvolvimento econômico dos países.

$\mathrm{Na}$ atual conjectura econômica, a realização do bem comum é o alicerce da força obrigatória dos contratos em contraposição ao ultrapassado dever moral de manutenção da palavra dada. Assim, hodiernamente, estamos diante de contratos padronizados e impessoais, comumente chamados de adesão, nos quais se nota a nítida crise da autonomia privada e a imposição de cláusulas sem negociação, logo o dirigismo contratual por meio da atuação do Estado se faz presente, a fim de que seja assegurada a supremacia da ordem pública e o efetivo equilíbrio contratual.

Destarte, o modelo atual da Teoria Contratual evoluiu conjuntamente com as necessidades da sociedade. Assim, nos séculos XVIII a XIX a fundamentação das contratações respaldou-se no princípio do pacta sunt servanda, ou seja, o contrato firmado fazia lei entre as partes, que ficavam obrigadas a cumprir o estabelecido no acordo de vontades, independentemente de vícios, desiquilíbrios.

Não obstante, referidos instrumentos eram utilizados de forma individualista, visando apenas os interesses dos contratantes, e não geravam efeitos a terceiros estranhos à relação contratual, salvo casos específicos e previstos pela legislação.

Já as inovações imposta pela sociedade capitalista e industrializada do século XX trouxeram emergentes e indispensáveis alterações ao que então se aplicava aos contratos, 
clamando que a promessa da igualdade política, deveria resguardar a almejada igualdade econômica, surgindo uma nova forma de contratar, mais complexa, apta a acompanhar as mudanças econômico-sociais que se impuseram.

Com o intuito de se entender a evolução dessa Teoria, denominada de Pós-Moderna ${ }^{1}$, a visão individualista é deixada de lado, dando origem a uma forma de contratar capaz de abranger a relação como um todo, pautada na função social do contrato e na boa-fé objetiva.

Baseado na breve exposição feita acima, este estudo será fruto de intensa pesquisa, iniciando-se pela análise histórica, com o intuito de discorrer sobre o surgimento dos contratos e sua evolução; utilizar-se-á da metodologia dedutiva, por meio da qual será feita análise do instituto jurídico do contrato e da legislação ordinária pertinente, bem como será empregado o método comparativo, não se esquecendo, por fim, da dialética, com o intuito de se confrontar pensamentos de grandes nomes do Direito sobre o tema, possibilitando concluir que a socialização contratual por nós hoje aplicada, tem como maior expoente no direito brasileiro o Código de Defesa do Consumidor.

\section{ORIGEM E EVOLUÇÃO DO CONTRATO COMO DECORRÊNCIA DA TRANSFORMAÇÃO SOCIAL}

Para dar início ao estudo do instituto jurídico dos contratos, tendo como arremate o surgimento e a aplicabilidade de uma nova teoria contratual, primeiramente se faz imprescindível entender a origem e a evolução desse instituto.

O civilista Clóvis Beviláqua (1916, p. 245) define contrato por "o acordo de vontade de duas ou mais pessoas com a finalidade de adquirir, resguardar, modificar ou extinguir direito."

Logo, a ideia principal a ser notabilizada é de que o contrato é considerado o negócio jurídico por excelência, meio através do qual as partes remediam a desconfiança existente entre si, em uma relação de troca e reciprocidade, gerando um equilíbrio mínimo de direitos e deveres.

\footnotetext{
${ }^{1}$ Utilizam-se de referida expressão: PAULO NALIN (NALIN, Paulo R. R. . Do contrato - Conceito PósModerno: Em busca da sua formulação na perspectiva civil-constitucional. $2^{\text {a }}$. ed. Curitiba: Juruá, 2006); HAROLDO CAMARGO BARBOSA (BARBOSA, Haroldo Camargo. Princípios Contratuais na Teoria Clássica e na Pós-Modernidade. Revista do Direito Privado da UEL. Vol1. N.2. Disponível em: http://www.uel.br/revistas/direitoprivado/artigos/Princ\%C3\%ADpiosTCl\%C3\%A1 ssicaHaroldoCamargo.pdf. Acesso: 22/3/2016); ROGERIO ZUEL GOMES (GOMES, Rogério Zuel. A nova ordem contratual: pósmodernidade, contratos de adesão, condiçães gerais de contratação, contratos relacionais e redes contratuais. Revista de Direito do Consumidor. N. 58. Disponível em http://www.gomesrosskamp.adv.br/artigos/Artigo1.pdf. Acesso: 22/3/2016).
} 
Não se pode deixar de enaltecer a definição moderna e inovadora do termo estudado, a qual busca a ampliação ou a remodelagem do conceito de contrato, criação essa fruto do jurista Paulo Nalin e discorrida pelo professor Flávio Tartuce, na qual o contrato constitui "a relação jurídica subjetiva, nucleada na solidariedade constitucional, destinada à produção de efeitos jurídicos existenciais e patrimoniais, não só entre os titulares subjetivos da relação, como também perante terceiros" (2005, apud TARTUCE, [200-?]).

Esta conceituação é de suma importância, pois elenca que o contrato se ampara em valores constitucionais, já que questões que envolvem direitos fundamentais refletem na autonomia privada. Ainda porque não deixa de dispor que a proteção individual da dignidade humana e dos interesses difusos e coletivos está protegida pelo princípio da função social do contrato e por último, por prever que o contrato pode gerar efeitos perante terceiros (TARTUCE, [200-?]).

Assim, contemporaneamente, como consequência da nova realidade social oriunda da sociedade de consumo, industrializada, massificada e hipercomplexa, na qual se revela a multiplicidade de fontes do direito, bem como a necessidade da defesa de inúmeros grupos sociais e, ainda a vasta quantidade de leis e decretos, nota-se que o direito contratual trespassou por considerável evolução e adaptação.

\subsection{Surgimento do Contrato: Direito Romano e Medieval}

Destarte, em razão da conveniência, o direito romano logrou instituir um conceito considerável sobre a ideia de contrato que, aliás, foi se desenvolvendo e se aperfeiçoando com o desenvolver dos séculos, segundo as necessidades da coletividade. Sintetizando, o contrato nasceu da realidade social, a qual se soma a respectiva organização econômica, como se passa a demonstrar.

O contrato no Direito Romano Clássico era dotado de três principais características: o formalismo, o materialismo e a atuação dos jurisconsultos na construção do ius civile (composto tão somente de normas costumeiras e raros preceitos legais) (MOREIRA ALVES, 1998, p. 68). Assim, o elemento primordial não era a vontade daquele que praticava a conduta, mas tão somente que esta estivesse em concordância com a forma (rito). Em outras palavras, pode-se dizer que não existia a figura do contrato tal como a conhecemos, mas se estava diante de um esquema formal de resultado vinculativo, fruto da baixa atividade jurídica (ROPPO, 2009. p.16). 
É valioso neste ponto aclarar que, tanto no antigo Direito Romano e no seu período Clássico, a formação do contrato respaldava-se na stipulatio, ou seja, na promessa feita de forma solene, em meio a uma cerimônia com aspectos sacramentais, da qual resultava a força obrigatória daquele pacto, denominada causa civilis, sendo o mais importante contrato daquela época (MARQUES, A., 2010, p.21).

No entanto, a evolução da economia mercantil e a velocidade das contratações encontravam no formalismo romano um sério entrave e, como rápida solução, a força obrigatória do contrato, por vezes, passou a advir de mero juramento religioso, obtendo-se com isso brevidade a conclusão das tratativas negociais.

Dessa forma, o resultado foi que a transposição para a Idade Média possibilitou a libertação dos contratos do formalismo romanista exagerado, porém a autonomia da vontadeaqui representada pelo amor a palavra empenhada- foi elevada a condição de elemento substancial do contrato, alicerçada na espiritualidade, logo a inexecução de uma obligatio estava ligada a ideia de pecado, em rompimento da fé jurada (MARQUES, A,, 2010, p. 27).

\subsection{O Contrato na Idade Moderna}

No início do século XIX, na França, passou a predominar a ideia do individualismo, fruto da teoria kantiana, momento no qual vigorou a visão antropocentrista, vindo a consagrar a liberdade e a igualdade política.

Sobre as influências da economia, da política e da sociedade impuseram-se mudanças gradativas de modo que os contratos assumiram a concepção de acordo de vontades, estabelecendo um vínculo jurídico sólido capaz de produzir efeitos jurídicos, cujo princípio norteador foi o pacta sunt servanda (BRAVO; SOUZA, 2001).

No âmbito político-econômico vigorou a doutrina do Liberalismo, que defendeu a liberdade econômica e política, segundo a qual a livre movimentação de riquezas era imprescindível para o desenvolvimento da sociedade, ganhando lugar a concepção da livre concorrência, dando aos contratantes maior independência para se auto-obrigarem, os quais, se reitera, quedavam adstritos ao princípio do pacta sunt servanda.

Portanto, esse dogma da liberdade contratual não se afastou da autonomia da vontade, pois ela continuou a legitimar o contrato, sendo pressuposto dessa vontade criadora. Dessa forma, pela força obrigatória dos contratos, as partes não poderiam se desvincular do pacto assumido, a não ser por outro acordo de vontades ou pela ocorrência do caso fortuito ou da força maior, em decorrência a função do magistrado limitava-se a assegurar que as partes 
atingiriam os efeitos pretendidos pela manifestação de vontade livre de vícios, mesmo que o conteúdo do contrato fosse injusto ou abusivo.

Sobre o acima exposto segue lição de Gustavo Tepedino (2004, p.3):

\begin{abstract}
A codificação como todos sabem, destinava-se a proteger uma certa ordem social, erguida sob a égide do individualismo e tendo como pilares, nas relações privadas, a autonomia da vontade e a propriedade privada. O legislador não deveria interferir nos objetivos a serem alcançados pelo individuo, cingindo-se a garantir a estabilidade das regras do jogo, de tal maneira que a liberdade individual, expressão da inteligência de cada um dos contratantes, pudesse se desenvolver francamente, apropriando-se dos bens jurídicos, os quais, uma vez adquiridos, não deveriam sofrer restrições ou limitações exógenas.
\end{abstract}

Nesse ínterim, as leis se limitavam a assegurar a concretização da plena autonomia da vontade expressada pelas partes e o cumprimento do avençado segundo a força obrigatória dos contratos, sendo que o conteúdo contratado se limitava a questões patrimoniais ou econômicas, assegurando a ideia de patrimonialidade (TARTUCE, [2000-]).

Essa concepção, embasada no sistematizador Savigny ${ }^{2}$ tinha, como anteriormente disposto, na vontade, o elemento norteador do contrato, pois era dela que se legitimava o pacto feito e seu poder vinculante e obrigatório.

No entanto, há que se clarificar que essa vontade deveria ser livre e real, isenta de vícios ou defeitos para que o contrato fosse válido. Concepção individualista, incorporada pelo ordenamento civil de 1916 no Brasil.

\title{
2.3. A Concepção Hodierna de Contrato
}

O surgimento da sociedade moderna, consequência da industrialização e da massificação das relações contratuais, requereu alterações na concepção tradicional do contrato, já que ganhavam espaço os contratos de adesão, que deixaram evidente o desiquilíbrio contratual, pois, neste modelo, a liberdade de contratar foi banalizada e a própria manifestação da vontade mostrou-se irrelevante.

No entanto essas mudanças não se fizeram de pronto modo, houve avanços e retrocessos, uma vez que interesses divergentes estavam em confronto, próprio das inovações econômicas. De um lado o clamor pela socialização do Direito, por meio de uma maior

\footnotetext{
${ }^{2}$ Friedrich Carl von Savigny influente jurista alemão do século XIX, opositor do jusnaturalismo iluminista, defendia que o Direito é vivo se modificando de acordo com a história e sociedade. PACHECO, Henrique $\begin{array}{llllll}\text { Olegário. As lições } & \text { de } & \text { Savigny. } & \text { Disponível } & \text { em }\end{array}$ http://www.revistapersona.com.ar/Persona79/79Pacheco.htm\#_ftn1. Acesso em 30/03/2016.
} 
inspeção social utilizando-se do Judiciário, objetivando a relativização da autonomia da vontade e, de outro lado, a Teoria Pura de Kelsen, focada no positivismo.

Assim, esse novo tempo, representado pela figura do Estado Liberal, resume uma nova óptica contratual na qual a atuação do legislador se volta para a função social que os institutos privados emanam, buscando a proteção e o alcance dos princípios sociais, com destaque para a dignidade da pessoa humana, com o intuito de diminuir sensivelmente as desigualdades nos campos cultural e material, além de permitir maior acesso da população aos direitos sociais (TEPEDINO, 2004, p.3).

Nessa vertente, vários são os artigos do Código Civil, a começar pelo aclamado artigo 421 que prega a liberdade de contratar a ser exercida em razão e nos limites da função social do contrato. No artigo seguinte, expressa-se o respeito a boa-fé contratual e a probidade ao longo de toda a contratação, além de constar, no artigo 187, como ato ilícito o exercício de direito fora dos limites da boa-fé e dos bons costume, em manifesta socialização do (outrora denominado) direito privado.

Vale-se deste momento para deslindar o êxito do ordenamento civil vigente em face do cravado Código de 1916.

Sucintamente, a transição do Código de Beviláqua para o Novo Código Civil de 2002, perfaz-se pela seguinte assertativa: "mudança do individual para o social” (TARTUCE, 2006, p.4).

Levando em consideração que a interpretação e criação jurídica inserem-se em um determinado ambiente politico-cultural, o Código de 1916 teve como escopo o "paradigma da modernidade, marcado pela racionalização do pensamento e da cultura e, principalmente, pela influência dos postulados do Estado de Direito" (AMARAL, 2005, P. 57), ou seja, a lei era a fonte do Direito, tendo por orientação o monismo jurídico, segundo o qual o Estado como criador das leis é a fonte suprema do Direito.

Já na a elaboração do Código de 2002, contou-se com a importante contribuição do jurista Miguel Reale, cujo maior efeito é a introdução da Teoria Tridimencional do Direito (fato, valor e norma) e do culturalismo jurídico no Brasil, deixando suas raízes nesse novo processo de codificação, contribuindo para uma interpretação da lei contrária ao positivismo, enaltecendo uma concepção axiológica-experimental da lei (REALE, 1994, P. 121)

Esses valores, sucintamente, podem ser entendidos da seguinte forma, o valor de justiça (sentido axiológico), o fato ligado ao social e histórico e, por fim, a norma como representação do ordenamento, do dever-ser. 
O Novo Código Civil passa então a ser a lei básica, mas não global do direito privado, como ensina Miguel Reale (1999, p. 48), pois a atual sociedade é mais complexa, pluralista, fragmentada. Logo, perdeu força o positivismo jurídico, pois os princípios jurídicos tem cada vez maior importância. Em complementação, perdeu espaço também o monismo, já que o Estado não é mais aceito como única fonte de Direito, ganhando expressão os costumes, a moral, os princípios gerais, a jurisprudência e a doutrina.

Ainda, para se captar a essência da concepção atual do Direito Civil, emprega-se a alteração de sua concepção frente o advento da $\mathrm{CF} / 88$, uma vez que aquele passou a ser enxergado como a transposição dos direitos individuais para os direitos sociais, ou seja, o Código Civil antes era visto como reflexo das relações privadas, não se confundindo com as matérias abarcadas pelo direito público.

Ocorre que com a maciça intervenção do Estado, restringindo a autonomia privada, buscando a proteção efetiva e o equilíbrio das relações contratuais, alterou profundamente o caráter de exclusividade no trato das relações patrimoniais ostentado pelo CC/1916 e o Texto Maior passou a ser um centro normativo comum, sendo reconhecido por sua supremacia frente aos demais ordenamentos (TEPEDINO, 2001, p. 5-6).

Logo, o Direito Civil perdeu seu papel de constituição do direito privado e a própria Constituição Federal passou a tratar de temas que antes lhe era inerentes (TEPEDINO, 2001, p.7).

Com toda essa mudança a Constituição Federal ocupou a centralidade da normatividade jurídica, determinando os critérios de interpretação das leis especiais, bem como do ordenamento civil, alcançando a reunificação do sistema (TEPEDINO, 2001, p. 13), tanto que a consequência direita foi a criação de um Novo Código Civil, sob a ótica social imposta.

A conclusão que se impõe é de que o CC de 2002 não se restringiu a tutela exclusiva do direito privado, tendo volta-se ao trato das relações existenciais, ou seja, o patrimônio perdeu primazia para a tutela da pessoa humana e, assim, dos direitos individuais (MORAES, 1999, p. 109). A esta nova visão denominou-se constitucionalização do Direito Civil, sendo que toda leitura deste diploma se valerá do conteúdo disposto no Texto Maior.

Diz-se que os pilares da sustentação do Direito Civil, família, propriedade e autonomia da vontade, deixaram de sê-lo. O único pilar que sustenta toda a estrutura é o do ser humano, a dignidade da pessoa, sua promoção espiritual, social e econômica. Este pilar está, por sua vez, enraizado na Constituição. (FIUZA, 2003, p. 29). 
Ressalta-se que essa releitura do ordenamento em face da supremacia da CF é aplicada a todos os diplomas, importando-nos no momento o CDC, que como fruto deste momento pós-moderno, em que se perdeu a importância da separação dicotômica entre direito publico e privado, a Constituição assume um papel dirigista, principalmente nos contratos de consumo, objetivando a promoção da justiça social (LOBO, 1995, p. 42).

Nesse novo âmbito, o sujeito de direito passa a ser entendido como "indivíduo situado" (REALE, 1999, p. 12) e não mais como uma figura meramente abstrata. Da mesma forma, o Estado passa a assumir um papel intervencionista, voltado para o bem estar social, dando lugar ao Estado Democrático de Direito.

Ainda como função do Estado, o liberalismo dá vez ao Estado Social, surgindo, o interesse social, até então elemento estranho a composição original do contrato.

Importante trazer à tona a posição do doutrinador civilista Orlando Gomes (2001, p. 32) para o qual se faz árdua a tarefa do operador do Direito na busca incansável da manutenção do equilíbrio entre a liberdade individual e a tutela ao interesse geral (social), defendendo que a intervenção Estatal nos contratos deve ser realizada dentro do razoável, para que não se comprometa a segurança jurídica do pacto firmado e sem que com isso haja um reflexo negativo no regime político-econômico do país. Esse posicionamento não se mostra antagônico ao anterior, mas de certa forma o limita:

Se o total liberalismo é censurável, também o excesso de intervenção no domínio dos contratos é incompatível com as ideias de liberdade e autonomia que se ligam aos direitos do homem no Estado Democrático de Direito.

Tal posicionamento serve como um parâmetro para a atuação da aplicação do direito contratual, uma vez que se mostra latente o dirigismo estatal nas contratações de consumo da sociedade pós-moderna, nas quais a autonomia da vontade desfalece ante as clausulas de adesão.

Embasado no acima exposto, observa-se que no Brasil, a concepção clássica do contrato entra em crise com o surgimento da nova ordem constitucional, tendo seu apogeu em 1991 com a promulgação do Código de Defesa do Consumidor, pois é nesta codificação socializada que descobrimos um novo papel da lei, trazendo de forma cogente, não apenas a defesa do consumidor, mas também prescrições de interesse social e de ordem pública (veja art. $1^{\circ}$ do $\mathrm{CDC}$ ), funcionando como verdadeiro instrumento apto a impor limites ao poder da vontade (MARQUES, C., 2006, p. 213). 
Ainda, há que se enaltecer que o código consumerista encontra amparo ao longo de toda a Constituição Federal, pois esta não deixou silente a questão da necessidade da proteção ao consumidor. Assim, ao longo de seu texto e em diversos temas, encontram-se expressos dispositivos análogos, a saber, dentro do titulo dos Direito e Garantias Individuais, o Texto Maior trás no artigo $5^{\circ}$, inciso XXXII, a máxima de que “o Estado promoverá, na forma da lei, a defesa do consumidor", este dispositivo é de extrema importância, pois se encontra inserido como forma de proteção da igualdade de tratamento a que os cidadãos brasileiro tem direito, ou seja, como Direito Fundamental.

Quando trata da organização do Estado, delega competência concorrente a União, Estados e Municípios para legislar sobre consumidor ${ }^{3}$ e no que concerne à tributação, impõe limites ao poder de tributar e determina que haverá medidas aptas a esclarecer aos consumidores quais são os impostos que incidem sobre mercadorias e produtos. ${ }^{4}$

Por fim, em relação à ordem econômica e financeira, a CF não se queda inerte ao dispor que a defesa do consumidor é um princípio a ser observado a fim de que seja assegurada a existência digna do cidadão, fundada na valorização do trabalho humano e na livre iniciativa. ${ }^{5}$

Ressalta-se, essa nova visão contratual está enraizada na Constituição Federal de 1988, ou seja, foram os próprios princípios constitucionais os amparadores da tutela da parte contratante mais fraca: interesse da coletividade, dignidade da pessoa humana. Logo, a interpretação contratual será filtrada nos princípios de ordem constitucional.

\subsection{A teoria contratual post modernidade}

Nesse novo paradigma contratual, a equidade e a Justiça vieram ocupar o centro da relação jurídica, em substituição a pura autonomia da vontade e ao individualismo, que, na conjectura da sociedade de consumo, tiveram o condão de fazer prevalecer o mais forte sobre o mais fraco, economicamente frágil, uma vez que o Projeto do Código Civil (PL 118/84) trouxe um novo balizador ao livre exercício da vontade: a 'função social do contrato' (MARQUES, C., 1999, p. 88), embora não tenha o legislador cuidado da conceituação do termo em análise, relegando esse papel a doutrina.

\footnotetext{
${ }^{3}$ Art. 24, VIII da CF

${ }_{5}^{4}$ Art. $150, \S 5^{\circ}$ da CF

${ }^{5}$ Art. $170, \mathrm{~V}$ da CF
} 
Observa-se com isso que a autonomia privada passa a ser interpretada e aplicada sob uma nova perspectiva jurídica, agora respaldada nos pilares da equidade, boa-fé contratual e segurança jurídica das relações contratuais, dessa forma, iniciou-se a socialização da teoria contratual, cujo principal escopo é o Código de Defesa do Consumidor, sem se olvidar da importante complementação proveniente do Código Civil.

Nesse novo momento, assiste-se à marcante função intervencionista Estatal, mudando consideravelmente os paradigmas, já que o princípio da boa-fé é exigido ao longo de toda a cadeia contratual, ou seja, tanto na formação, quanto na execução das obrigações.

Enaltece-se que, apesar de ser posterior ao Código de Defesa do Consumidor, o Código Civil de 2002, como já aludido, também é fruto da nova concepção contratual, pois tem suas raízes nos princípios norteadores da ordem constitucional de 1988. Nesse sentido, elucida o Enunciado n. ${ }^{\circ} 167$ da III Jornada de Direito Civil:

Com o advento do Código Civil de 2002, houve forte aproximação principiológica entre esse Código e o Código de Defesa do Consumidor, no que respeita à regulação contratual, uma vez que ambos são incorporadores de uma nova teoria geral dos contratos. (ASCENÇÃO, 2008, p.2)

Em contrapartida ao posicionamento jurídico exposto, Tepedino (2004, p. 19) defende que, o Código de Defesa do Consumidor não pode representar uma nova fase contratual, pois, se assim for entendido, estar-se-á dando ensejo a um sistema fragmentado e afastado do seu Texto Maior.

Conclui o doutrinador que, os princípios elencados no CDC devem ser utilizados de maneira irrestrita, já que consolidados no Sistema Jurídico Brasileiro, sendo tais princípios tradução da tábua axiológica do sistema constitucional e não de um microssistema fragmentado. Logo, a força deste código não se reduz às suas próprias normas, mas sim a ordem constitucional que o assegura e o fundamenta.

Finaliza sustentando que a reunificação do ordenamento, superando as repartições feitas no passado, bem como a dicotomia entre direito publico e privado seria o que poderíamos denominar de nova teoria contratual compatível com o momento atual.

O pensamento supracitado representa uma nova postura metodológica, na qual se torna imprescindível realizar toda e qualquer leitura do Direito Civil e do Direito Consumerista em uma perspectiva dialética com a Constituição Federal. No entanto, esse entendimento, apesar de parecer contrário a linha de pensamento que se aponta, na verdade, é 
mero enaltecimento da conjectura constitucional, uma vez que, a ideologia contida no CDC e no CC/2002 não se sobrepuseram aos princípios basilares da CF/88.

Isso posto, as necessidades oriundas da pós-modernidade, apenas foram especificamente abrangidas e consolidadas pelo Código de Defesa do Consumidor que, efetivamente, tratou da vulnerabilidade de uma das partes contratantes, pelos motivos elencados por J. Oliveira Ascensão (2008, p. 24):

O Código Civil é sábio e suporta a estruturação dum Direito de cláusulas gerais. Infelizmente, nasceu velho e não foi objeto da revisão necessária. O Código do Consumidor adiantara-se muito mais, na transposição setorial do novo espírito ancorado na Constituição de 1988.

Portanto, outra conclusão não se impõe a não ser a de que tanto o Código Civil como o Código de Defesa do Consumidor possuem uma visão constitucionalizada em matéria contratual, uma vez que tanto num diploma como no outro, a despeito de inexistir consumidor na esfera civilista, existirá, principalmente nos contratos de adesão, vulnerabilidade de uma das partes, a qual será tutelada com embasamento na dignidade da pessoa humana e na função social do contrato. Com efeito, o enfoque do Código de Defesa do Consumidor é minimizar a exacerbada desproporção das obrigações, revigorando o equilíbrio real entre os contratantes, em favor da parte mais fraca da relação jurídica instaurada.

A lei 8.078/1990 é um microssistema jurídico construído e organizado para tutelar um sujeito especifico, o consumidor. Consequentemente, sua função é compensar as desigualdades sem interferir na estrutura ou tipo de relação jurídica (PASQUALOTTO, 2011).

Complementa-se que referido texto é uma lei de função social, pois elenca normas de direito privado indisponível, bem como normas de direito público (MARQUES, C., 2009, p. 47). Assim, sucede-se uma verdadeira relativização dos princípios da teoria contratual clássica, por meio de normas que vão orientar o intérprete pela busca da Justiça e do equilíbrio nas relações de consumo. Portanto este código é uma concretização da função social do contrato, difundindo novamente a ideia de socialização disposta na Constituição Republicana (art. $\left.3^{\circ}, \mathrm{I}\right)$.

Nesses ditames, são importantes conquistas à definição legal do contrato de adesão, a não obrigatoriedade dos pactos em que o não for atendido o direito de informação prévia ao consumidor ou se sua redação foi dificultosa a compreensão de seu alcance, além de trazer regras de interpretação das cláusulas contratuais mais favoráveis ao consumidor, a vinculação 
dos fornecedores às obrigações assumidas em contratos preliminares, o direito de arrependimento, dentre outras (AZEVEDO, 2013, p. 219-223).

\section{CRISE NA PÓS-MODERNIDADE: A NOVA TEORIA CONTRATAL}

Nesse tópico passaremos a analisar as principais implicações trazidas pelo código consumerista, sem, no entanto, deixar de ressaltar que a principal intenção dessa nova ordem contratual, de proteção ao consumidor, não visa sepultar a liberdade contratual, mas adequá-la a nova realidade social e econômica vivida.

Conforme já elucidado nesse trabalho, o Direito é criação humana e como tal serve para atender às suas necessidades, consequentemente, se não mais é hábil a atender esses anseios, mostra-se imprescindível sua renovação e adaptação para que novamente possa regular as relações interpessoais. Dessa forma, sendo a mais importante fonte de obrigações, o contrato não pode ter caminho diferente, logo, o ideal de contrato estará diretamente associado à moral, às praticas sociais e à economia.

Com as revoluções do presente, teve início o que se denominou de socialização do direito contratual, sendo que autores europeus denominam este momento de ruptura e o relacionam a várias alterações políticas e sociais, na qual impera o capitalismo neoliberal com efeitos perversos e exclusão social, da terceirização, das privatizações, da multiplicidade de cultura, da globalização, da informatização e de tantas outras visões negativas, por fim é a crise do Estado de Bem-Estar Social.

No campo jurídico, ensina Jayme Erick (1993, apud MARQUES, C., 1999) que as consequências aparentes para o Direito seriam o Pluralismo, a Comunicação, a Narração, sendo o ápice a valorização dos direitos humanos, afirmando que o direito, como parte da cultura dos povos, muda a crise.

Pluralismo, brevemente, constitui-se como a multiplicidade de fontes legislativas capazes de regulamentar o mesmo fato, pode ainda se referir a pluralidade de sujeitos ativos ou passivos, representando um grupo com interesse comum.

Comunicação se expressará como a valorização da vontade associada ao Direito, como fonte de comunicação e de informação.

Por fim, a Narração é consequência da comunicação, pois, nesse novo modelo, as ordens jurídicas não são mais impositivas ou meramente reguladoras de condutas, mas sim normas que expressem o real objetivo do legislador, fixando e auxiliando a interpretação da norma no futuro. 
Assim, essa crise do direito contratual resultou na mudança de um modelo de contratação sem mobilidade para um modelo dinâmico, de contratos bilaterais para multilaterais. Conclui-se, como anteriormente dito, que essas alterações resultaram na valorização dos princípios, em maior importância a Justiça e a equidade e, primordialmente a utilização do paradigma da boa-fé como norte da aplicação da vontade das partes.

Ressalta-se, novamente, que nesse novo momento de socialização do direito civil, a teoria contratual contemporânea, que embasará o Código de Defesa do Consumidor, explicita em seu texto o respeito a novos princípios contratuais, que são capazes de atender aos anseios sociais e aos efeitos que os contratos causam na sociedade. Não se fechando os olhos, obviamente, para a capacidade econômica e a condição intelectual dos contratantes.

Os princípios da autonomia da vontade e da força obrigatória dos pactos permanecem sendo respeitados, no entanto, são colocados na balança do equilíbrio contratual. Surgem então normas imperativas, regulamentadoras do interesse social, responsáveis por impor limites à autonomia privada, alterando a concepção clássica deste elemento, que passa a ser acompanhada pelos princípios da equidade, boa-fé objetiva e segurança jurídica.

Com clareza explica Antônio Herman V. Benjamim (1999, p.9), um dos redatores do Código de Defesa do Consumidor, que a problemática de proteção contratual ao consumidor não é um problema brasileiro ou apenas dos países de terceiro mundo, mas sim de importância universal, pois, os problemas e as inovações elencadas repercutiram na forma de contratar de todo o universo capitalista, abrangendo, até mesmo, os países que utilizam o modelo socialista mas que pactuam e comercializam com o mundo capitalista, assim, apenas para elucidar, a necessidade de atender a proteção do consumidor vem sendo tratada por legisladores desde o Código Civil italiano de 1942.

Voltando para a necessidade brasileira, o redator elucida que antes da vigência do diploma consumerista não havia sentido em se falar em mecanismos de proteção ao consumidor, já que referida legislação não existia como entidade jurídica de perfil próprio, portanto, ficava limitada a um esforço da jurisprudência na tentativa de amenizar o rigor do Código Civil de 1916 e o apego da doutrina a certos princípios que não mais satisfaziam os clamores da sociedade de produção e consumo em massa. (BENJAMIM, 1999, p.9)

\subsection{A boa-fé contratual e a função social}

O princípio da boa-fé passa a ser o novo standart da relação contratual, estampado no novo paradigma denominado $\mathrm{CDC}$, este princípio, tal como se conhece, tem sua origem 
remota na fides do Direito Romano, a qual passou a fides bona e à bona fides, sendo incorporada ao direito como bona fidei iudicia (ROCHA, 1984, p. 71), entendida como o habito de honrar seus compromissos, isto é, fidelidade no cumprimento da obrigação firmada.

Nesse momento, deixa de se ater ao formalismo estrito para se buscar uma solução material, tal como o reconhecimento implícito da equivalência das obrigações, assim, "a bona fides como norma objectiva de conduta correcta ou da funcionalidade das obrigações (...)". (ROCHA, 1984, p. 71)

Resulta que, no período clássico, a boa-fé tinha natureza de norma jurídica objetiva referente a um comportamento correto e honesto, respeitando a honestidade e os costumes da época. (ROCHA, p. 105)

Pode-se dizer, dessa forma, que na conjectura atual mantém-se o sentido da palavra, contudo, sua significação e aplicação foram ampliadas, passando a abranger a relação obrigacional como um todo, ou seja, a boa-fé deve ser respeitada no momento pré-contratual, na elaboração, na execução e até mesmo após o término da obrigação, o que se exterioriza pelos deveres de conduta, como o direito à informação, dever de cooperação, dever de lealdade. Portanto, os contratantes não estão obrigados somente à obrigação principal estampada, mas, também, a todos os deveres anexos que dela decorrerem, denominadas, usualmente, de obrigações acessórias.

Expresso nos artigos $4^{\circ}$, inciso III e 51, IV do Diploma Consumerista, pode-se claramente ver a importância basilar da boa-fé objetiva:

\begin{abstract}
Art. $4^{\circ}$ A Política Nacional das Relações de Consumo tem por objetivo o atendimento das necessidades dos consumidores, o respeito à sua dignidade, saúde e segurança, a proteção de seus interesses econômicos, a melhoria da sua qualidade de vida, bem como a transparência e harmonia das relações de consumo, atendidos os seguintes princípios:

III - harmonização dos interesses dos participantes das relações de consumo e compatibilização da proteção do consumidor com a necessidade de desenvolvimento econômico e tecnológico, de modo a viabilizar os princípios nos quais se funda a ordem econômica (art. 170, da Constituição Federal), sempre com base na boa-fé e equilíbrio nas relações entre consumidores e fornecedores;
\end{abstract}

Art. 51. São nulas de pleno direito, entre outras, as cláusulas contratuais relativas ao fornecimento de produtos e serviços que:

IV - estabeleçam obrigações consideradas iníquas, abusivas, que coloquem o consumidor em desvantagem exagerada, ou sejam incompatíveis com a boa-fé ou a equidade;

A renovação da teoria contratual deve-se às alterações econômicas vividas, ao intervencionismo estatal compreendido em todos os setores: judiciário, legislativo e administrativo e a institucionalização dos contratos. 
Logo, a visão atual de contrato, deve ser baseada na sua função social e não ser lido estritamente às luzes da autonomia privada. Deve-se entender função social do contrato como o parâmetro a ser observado pelo aplicador do Direito, pois atua como instrumento de justiça social, visa a proteção do interesse dos contratantes, os interesses sociais e de terceiros não contratantes, assim nos dizeres de Nelson Nery Junior (2003, p. 336):

\begin{abstract}
O contrato estará conformado à sua função social quando as partes se pautarem pelos valores da solidariedade $\left(\mathrm{CF}\right.$, art. $\left.3^{\circ}, \mathrm{I}\right)$ e da justiça social (CF, art. 170caput), da livre-iniciativa, for respeitada a dignidade da pessoa humana $\left(\mathrm{CF}\right.$, art. $1^{\circ}$,III), não se ferirem valores ambientais (CDC, 51, XIV) etc.
\end{abstract}

Não resta dúvida que o Código de Defesa do Consumidor seja a maior expressão de normas cogentes disciplinadoras da relação entre contratante e contratado, consumidor e fornecedor, portanto, os princípios outrora basilares de qualquer negociação perdem seu conceito primário e devem ser relidos sob o novo paradigma imposto, não se esquecendo dos ditames constitucionais.

Nesse conceito, a liberdade contratual pode ser limitada e, por vezes, até mesmo imposta, dando azo ao que se chama de dirigismo contratual. Porque o Estado ganhou poder de intervenção, além de controle judicial e administrativo, podendo, inclusive, proibir a inserção de cláusulas que entende ser abusivas, em claro atendimento aos princípios contratuais da boa-fé e da função social do contrato, dentre outros.

Quanto ao controle estatal, esclarece-se que também reflete no princípio da força obrigatória dos contratos, já que poderão ser editadas leis específicas e, ainda, ser analisada a vinculação do trato em cada caso concreto, por meio da atuação do Judiciário.

Nesse novo âmago, os contratos deixam de vincular apenas as partes, pois são analisados para atender os interesses da coletividade. O fim almejado pelas normas jurídicas é a proteção dos efeitos dos contratos na sociedade, no meio em que se inserem, buscando a assimilação do objetivo pretendido pelas partes e a justiça social.

Consequentemente, o que se percebe na doutrina e na jurisprudência brasileira, é que há um anseio por aplicar simultaneamente os princípios da autonomia da vontade e da boa-fé, não os contrapor. Assim, visualizamos uma importante alteração na visão do aplicador da lei, que atuará, não apenas para proteger a autonomia privada do profissional, mas também criará técnicas de proteção ao consumidor, entendido como parte vulnerável na cadeia de consumo, garantindo com isso a autonomia real da vontade do contratante mais fraco (MARQUES, C., 1999, pp. 129 -130). 
Com isso, a análise dos contratos não fica adstrita a institutos jurídicos em especifico, como coação, caso fortuito, força maior e estado de necessidade, mas será feita utilizando-se de um olhar sobre a própria sociedade, suas desigualdades, sobre a necessidade da parte em ter firmado aquele contrato, sem poder contra seus termos se opor frente a desigualdade técnica (ex. contrato bancário, planos de saúde, financiamento imobiliário).

Ressalta-se, trata-se de uma proteção real, a ser verificada em cada circunstância, voltada ao socorro daquele indivíduo situado no mundo jurídico e na sociedade e, para alcançar esse reequilíbrio nada melhor que a efetiva aplicação da boa-fé e da função social do contrato.

\section{CONCLUSÃO}

Vigora a aplicação de uma nova teoria contratual, fruto da evolução e das necessidades de diversas civilizações em diferentes momentos históricos e situações econômicas.

Há, como elencado, doutrinadores que não são adeptos a esta corrente, no entanto, mostram-se a minoria deste universo post modernidade, momento no qual se volta a atenção à proteção do consumidor, ao equilíbrio real entre as partes contratantes, a aplicação da boa-fé e da função social do contrato.

Assim, vivemos a socialização do direito contratual, podendo até mesmo se arriscar a dizer que o mundo como um todo, ou ao menos a civilização oriental, compreendeu a necessidade de se criar mecanismos amenizadores dos efeitos díspares dos contratos de massa, possibilitando a proteção daqueles que não tem meios de discutir ou modificar o conteúdo das convenções.

Em termos globais, nisso resultou a criação das cláusulas gerais para os contratos, a exemplo, no Direito Português foram disciplinadas no decreto lei 446/85; no ano de 1976 o Conselho da Europa recomendou aos Estados a confecção de instrumentos legislativos aptos à proteção do consumidor e estabeleceu diretrizes concretas e, no Direito Brasileiro tivemos como resultado o Código de Defesa do Consumidor (GOMES, L. R. F., 1999, p. 99).

Resumidamente, podemos elencar que aplicação do Código de Defesa do Consumidor, como expoente máximo da nova teoria contratual, acompanha todo o tramite contratual. $\mathrm{Na}$ fase pré-contratual se vale do Princípio da Transparência, garantindo o direito à informação pormenorizada dos objetivos, bem como do conteúdo e dos termos contidos nas cláusulas. 
Durante todas as etapas contratuais o princípio basilar e norteador dessa nova era protecionista é a Boa-Fé, impedindo que os fornecedores se beneficiem da vulnerabilidade do consumidor.

O equilíbrio efetivo das relações de consumo terá como escopo balizar a desigualdade real existente entre as partes contratantes, voltado à realização da Justiça Contratual, aplicando-se para tal fim o Princípio da Equidade Contratual.

Não menos importante, o novo Diploma baseia-se no Princípio da Proteção da Confiança, alicerçando a verdadeira expectativa que levou àquela contratação, garantindo uma segurança razoável, trata-se de um aspecto subjetivo voltado à proteção daquele que justificadamente confiou em outrem e posteriormente houve discrepância com o que resultou no final.

Ante o acima exposado, deduzimos que o real interesse do CDC não é criar privilégios, mas a proteção da parte vulnerável, equiparando-se os deveres e direitos de partes que na realidade mostram-se desiguais, passando da concepção de direito taxativo para direito valorativo.

A nova teoria contratual é a do retorno à substância e a da complementação indispensável dos enunciados legais por princípios e valorações. (ASCENÇÃ̂, p.28)

Por fim, os princípios da autonomia privada e da força obrigatória dos contratos, emanados de bases individualistas e que eram indissociáveis da concepção clássica de contrato, perdem seu caráter central, pois incapazes de atender a socialização do direito, portanto é a nova ordem contratual, revelada no ordenamento jurídico brasileiro por meio do CDC que trará sustentação a igualdade formal entre as partes contratantes, exigida pela massificação dos contratos, ao interesse social centrado na dignidade da pessoa humana, colocando o consumidor como cerne da evolução da sociedade, do crescimento da economia e por isso merecedor de amparo jurídico.

Resta, por fim, clarificar que a legislação consumerista brasileira não é apta a alcançar todos os anseios de nossa sociedade e solucionar todas as desigualdades provenientes dos contratos de massa, há muito que se conquistar, no entanto, não se pode negar que seus princípios basilares, conjugados com as previsões do Código Civil e sempre subordinados as cláusulas pétreas constitucionais, possibilitaram a passagem do liberal e individualista para um olhar social, engrandecendo o Direito como garantidor do equilíbrio real, da confiança 
mútua e das legítimas expectativas nas contratações, causando uma importante revolução no modo de contratar, possibilitando a socialização do Direito Contratual em uma nova teoria.

\section{REFERÊNCIAS BIBLIOGRÁFICAS}

AMARAL, Francisco. O Código Civil brasileiro e o problema metodológico de sua realização. Do paradigma da aplicação ao paradigma jurídico-decisório.In: RBDC. Instituto de Direito Comparado Luso-brasileiro, 2005. v. 28.

ASCENÇÃO, J. Oliveira. A Nova Teoria Contratual. Belo Horizonte: Rev. Fac. Direito UFMG, n. 52, p. 97-126, jan./jun. 2008. Disponível em http://www.direito.ufmg.br/revista/index.php/revista/article/viewFile/66/62. Acesso em 29/12/2015.

AZEVEDO, Fernando Costa de; KLEE, Antonia Espindola Longoni. Considerações sobre a proteção dos consumidores no comércio eletrônico e o atual processo de atualização do Código de Defesa do Consumidor. Revista de Direito do Consumidor, São Paulo: Ed. Revista dos Tribunais, jan./fev. 2013. v. 22, n. 85.

BENJAMIM, Antonio Herman V. Apresentação ao Livro de MARQUES, Claudia Lima. Contratos no Código de Defesa do Consumidor. 3ed. São Paulo: Ed. Revista dos Tribunais. 1999. Vol I.

BENJAMIN, Antônio Herman; MARQUES, Cláudia Lima; BESSA; Leonardo Roscoe. Manual de Direito do Consumidor. $2^{\circ}$ Edição. São Paulo: Editora Revista dos Tribunais. 2009.

BEVILÁQUA, Clóvis. Código civil anotado. Rio de Janeiro: Francisco Alves, 1916. vol. 4.

BRAVO, Maria Celina; SOUZA, Mário Jorge Uchoa. $O$ contrato do terceiro milênio. Teresina: Revista Jus Navigandi, 2001. Ano 6, n. 52, 1 nov. Disponível em: <https://jus.com.br/artigos/2365>. Acesso em: 29 dez. 2015.

FIÚZA, Cesar. Crise e interpretação no direito civil da escola da exegese as teorias da argumentação. In: FIUSA, Cesar. FREIRE DE SÁ, Maria de Fatima; NAVES, Bruno Torquato de Oliveira. Direito Civil- Atualidades. Belo Horizonte: Del Rey, 2003.

GHERSI, Carlos Alberto. La Posmodernidad Juridica- Una discussion aberta, Buenos Aires: Ed. Gowa, 1995.

GOMES, Orlando. Contratos. 24 ${ }^{\mathrm{a}}$ ed. Rio de Janeiro: Forense, 2001.

GOMES, Luiz Roldão de Freitas. Contrato. Ed 1. Rio de Janeiro: Renovar, 1999.

LISBOA, Roberto Senise. Contratos Difusos e Coletivos: consumidor, meio ambiente, trabalho agrário, locação, autor. São Paulo: RT, 1997.

LOBO, Paulo Luiz Neto. Contrato e mudança social. São Paulo: Revista dos Tribunais, dez. 1995, v. 722. 
MARQUES, Adria Rodrigues. Contratos: panorama histórico e principiologia contratual. Franca: Unesp, 2010.

MARQUES, Claudia Lima. Contratos no Código de Defesa do Consumidor. 3ed. São Paulo: Revista dos Tribunais, 1999. Vol I.

Contratos no Código de Defesa do Consumidor. $O$ novo regime das relações contratuais. $5^{\text {a }}$ ed. São Paulo: Editora Revista dos Tribunais, 2005.

MORAES, Maria Celina Bodin de. Constituição e direito civil: tendências. Revista Direito, Estado e Sociedade. [S.1], , ago./dez. 1999, n. 15.

MOREIRA ALVES, José Carlos. Direito Romano. 11ed. Rio de Janeiro: Editora Forense. 1998. Vol.I.

NERY JÚNIOR, Nelson; NERY, Rosa Maria de Andrade. Código Civil Anotado e Legislação Extravagante. São Paulo: Revista dos Tribunais, 2003.

PASQUALOTTO, Adalberto. Dará a reforma ao Código de Defesa do Consumidor um sopro do vida?. Revista de Direito do Consumidor. Ano 20, vol.78, abr. - jul./2011.

REALE, Miguel. Exposição de Motivos do Anteprojeto de Código Civil, in O Projeto do Novo Código Civil. São Paulo: Editora Saraiva, 1999,

REALE, Miguel. Teoria tridimensional do direito. $5^{\text {a }}$ ed. rev. e aum. São Paulo: Saraiva, 1994.

ROCHA, Antonio Manoel da; CORDEIRO, Menezes. Da boa fé no Direito Civil. Coimbra: Livraria Alemdina, 1984. Vol I.

ROPPO, Enzo. O Contrato. Edições Coimbra: Almedina, 2009.

TARTUCE, Flávio ;CASTILHO, Ricardo (Coord.). Direito Civil. Direito Patrimonial e Direito Existencial. Estudo em Homenagem À Professora Giselda Maria Fernandes Novaes Hinoraka. São Paulo: Editora Método, 2006.

TARTUCE, Flávio. O Conceito de Contrato na Contemporaneidade. [200-]. Disponível em http://www.flaviotartuce.adv.br/index2.php?sec=artigos\&id=48. Acesso em 29/3/2016.

TEPEDINO, Gustavo. Temas de Direito Civil, $3^{\circ}$ ed. Rio de Janeiro: Ed. Renovar, 2004. Pp. 217 e ss. Artigo: As relações de consumo e a Nova Teoria Contratual. Disponível em http://www.tepedino.adv.br/wp/wp-content/uploads/2012/09/biblioteca6.pdf Acesso em 22/12/2015.

. Temas de direito civil. 2. ed. rev. atual. Rio de Janeiro: Renovar, 2001. 